\title{
Diagnóstico y manejo de hidramnios
}

\author{
Leonor Zapata*
}

Es definido como la acumulación excesiva de líquido amniótico, unos $2.000 \mathrm{ml}$ al final de la gestación, este es el concepto clásico donde quedan excluidas ciertas acumulaciones agudas de líquido presentes en etapas más tempranas del embarazo (1).

Es una complicación de la gestación de origen complejo, causante de severas complicaciones fetales y maternas responsables de una alta morbimortalidad, de allí la importancia del tema.

Incidencia. Fluctúa entre un 0,26 a 3,93\% (2-3).

Clasificación. Hay dos tipos de hidramnios: 1) Crónico, el más frecuente de instauración lenta, etiología diversa y rara vez necesita descompresión. 2) Agudo, de aparición brusca en el segundo trimestre, la mayoría de las veces idiopático o asociado al embarazo gemelar (2).

Diagnóstico. Se hace de varios métodos.

I. Clínico. Sospechamos su presencia cuando tenemos una altura uterina mayor a lo esperado para edad gestacional, peloteo de partes fetales, a la percusión del abdomen materno hay sensación de oleada, dificultad en palpar partes fetales y auscultar los latidos cardíacos.

II. Ecosonografía. Método capaz de visualizar al feto en su medio ambiente, no invasivo y en la actualidad ha desplazado otras técnicas diagnósticas. Ecográficamente se han descrito tres observaciones: feto desplazado a la pared posterior del útero, miembros fetales flotando libremente en el tercer trimestre y magnificación de las imágenes correspondientes al cordón umbilical (1).

Midiendo la bolsa amniótica diversos autores han hecho determinaciones cualitativas de la cantidad de líquido amniótico, Chamberlain y col. (4) usan una medida vertical de la bolsa $>8 \mathrm{~cm}$ para hacer diagnóstico de hidramnios asociado a malformaciones. Phelan y col. (5) describen el índice de líquido amniótico (ILA) para obtenerlo suman las mediciones de la bolsa en cuatro cuadrantes del útero y presentan sus valores entre las semanas 36 y 42 de gestación, un ILA de $20 \pm$ $4.7 \mathrm{~cm}$ en la semana cuarenta corresponde a un hidramnios.

En el segundo trimestre pueden haber acumulaciones transitorias de líquido amniótico, en estas circunstancias la ecosonografía debe repetirse en una semana (1).

Departamento Obstetricia y Ginecología, Maternidad Concepción Palacios, Caracas.

\section{Etiología}

I. Causas maternas. Cualquier enfermedad que transforme a la madre en un medio hostil puede originar hidramnios, tradicionalmente se han descrito la diabetes y la inmunización Rh como las causas más frecuentes pero con el adecuado control metabólico de las diabéticas y el uso profiláctico de la Rh-inmunoglobulina, éstas han disminuido su importancia como factor causal. II. Causas fetales. Se describen múltiples malformaciones congénitas causantes del hidramnios, las cifras varían entre 12,7 a $20 \%(2,6)$. Las anomalías más frecuentes descritas son: 1) Anomalías del sistema nervioso central. Anencefalia, hidrocefalia, lesiones abiertas del tubo neural.

2) Anomalías gastrointestinales. Toda malformación que obstaculice la deglución o absorción del líquido, las atresias esofágica y duodenal son las más frecuentes.

3) Alteraciones circulatorias. Arritmias y miocardiopatías. El hidrops no inmunológico en un $50 \%$ se acompaña de hidramnios y su origen es cardíaco en un $20 \%$.

4) Tumores fetales. Teratomas cervicales y sacrococcígeos.

5) Alteraciones musculoesqueléticas. Cualquiera alteración puede asociarse a hidramnios.

6) Cromosomopatías. Trisomías 18 \& 13, síndrome de Turner, anillo cromosómico.

III. Embarazo gemelar. Muy importante por el aumento de incidencia provocado por las drogas inductoras de la ovulación usadas con mucha frecuencia en la actualidad. En gemelos se presenta en un $8,4 \%$ (2).

IV. Anexos. Los tumores placentarios como: corioangiomas o los quistes placentarios. Los nudos del cordón umbilical.

V. Infección intrauterina. Enfermedades como sífilis y las del grupo TORCH.

VI: Idiopático. A pesar de estudiarse exhaustivamente a la madre y al feto no puede explicarse la asociación de hidramnios, su frecuencia varía entre un 34 a $65 \%(2,6)$.

Conducta. Una vez establecido el diagnóstico proceder de la forma siguiente:

Feto sin anomalías. Descartar diabetes, sífilis, TORCH. En caso de pruebas negativas, clasificarlo como de origen idiopático.

Feto con anomalías. Amniocentesis o cordocentesis para cariotipo. En pacientes con dolor abdominal, molestias respiratorias, contracciones uterinas prematuras administrar indometacina a una dosis de $50 \mathrm{mg}$ cada 8 horas con las comidas. Realizar una ecocardiografía previa a la 
administración del medicamento para valorar el ducto arterioso fetal, repetirla a las 24 horas y luego cada semana. Medir el ILA semanalmente (3, 6-8).

Las valoraciones fetales deben incluir el perfil biofísico y la vigilancia electrónica de la frecuencia cardíaca intraparto. El recién nacido será valuado por el neonatólogo y en caso de óbito fetal tomar muestra de sangre para cariotipo; radiografía y autopsia del natimuerto. La placenta y el cordón umbilical serán estudiados microscópicamente; de esta manera se obtiene un diagnóstico definitivo.

Complicaciones. Son múltiples: partos prematuros, presentaciones viciosas, desprendimiento placentario y hemorragia postparto.

La mortalidad perinatal varía entre 32.9/1000 gruesa y 4.12/1000 corregida (4).

\section{BIBLIOGRAFIA}

1. Moore PT, Mencini R, Spitz HB. Sonografic Diagnosis of Hydramnios and Oligohydramnios. Seminars in Ultrasound CT and MR 1984; 5 : 157-169.

2. Loy G, Queenan JT. Clinical Aspects of Amniotic Fluid Volume. Postgraduate Obstetrics \& Ginecology 1989; 9: 1-5.

3. Sosa Olavarría A. Patología del líquido amniótico. En: Ultrasonografía y Clínica Embrio fetal. Ed. Tatum CA, Valencia, 1993; 277-289.

4. Chamberlain PF, Manning FA, Morrison I, Harman CR, Lange IR. Ultrasound evaluation of amniotic fluid volume II. The relationship of increased amniotic fluid volums to perinatal outcome. Am. J. Obstet. Gynecol. 1984; 150: 250-254.
5. Phelan JP, Smith CV, Broussard P, Small M. Amniotic fluid volume assessment with the Four-Quadrant Technique at 36-42 weeks gestation. J. Reprod. Med. 1987; 32: 540-542.

6. Arias F. Dismorfología fetal. En: Guía práctica para el embarazo y el parto de alto riesgo. 2da. Ed. Mosby/Doyma Libros, Madrid. 1995; 326-362.

7. Niebil JR. Perinatal effects of Indometacin. Postgraduate Obstetrics \& Ginecology 1991; 11: 1-5.

8. Kirshon B, Mari G, Moise KJ, Jr. Wasserstrum. Effect of indomethacin on the fetal ductus arteriosus during treatment of symptomatic polihydramnios. J. Reprod. Med. 1990; 35: 529-532.

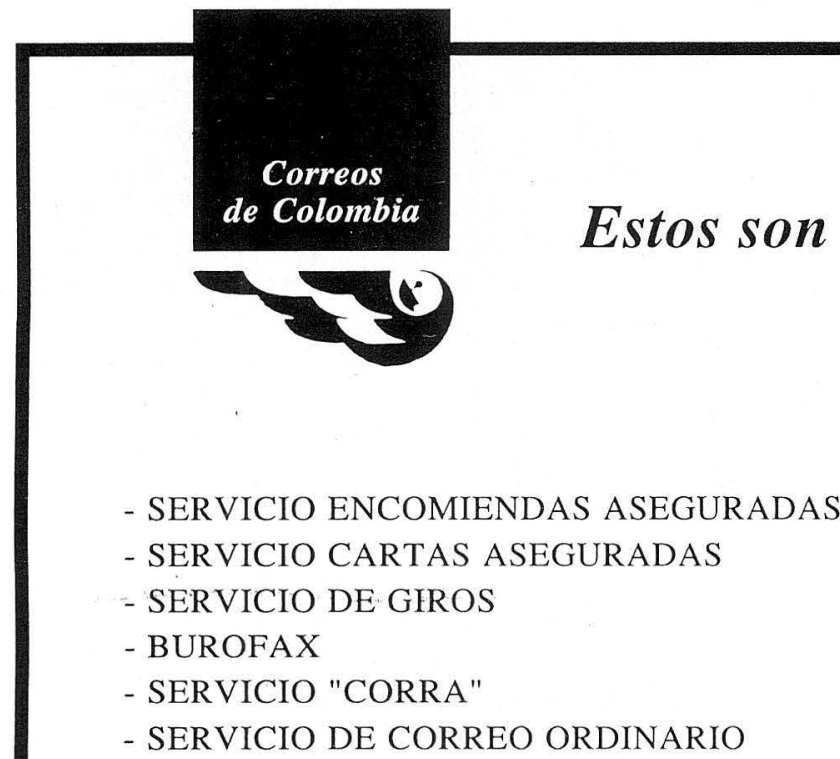

- SERVICIO DE CORREO CERTIFICADO

- SERVICIO DE CERTIFICADO ESPECIAL

- ENCOMIENDAS CONTRA REEMBOLSO

- SERVICIO TARIFA POSTAL REDUCIDA

- SERVICIO DE FILATELIA

- SERVICIO ELECTRONICO

- SERVICIO INTERNACIONAL APR/SAL

- SERVICIO RESPUESTA COMERCIAL

- SERVICIOS ESPECIALES

Teléfonos para quejas y reclamos: 3340304 - 3415536 - Santafé de Bogotá, D.C. - Colombia Cuente con nosotros hay que creer en los Correos de Colombia 